\title{
Study on Real Economy Development and Supply Chain Finance in Look Forward to Beijing-Tianjin-Hebei Region
}

\author{
Xiangjun $\mathrm{He}$ \\ School of Safety and Environmental Engineering, Capital University of Economics and Business, \\ Beijing, 100021
}

Keywords: supply chain finance in Beijing-Tianjin-Hebei Region, real economy

\begin{abstract}
Beijing-Tianjin-Hebei Region is how to develop real economy and thus fund will become a barrier. This paper has discussed the industry positioning in Beijing-Tianjin-Hebei Region and proposed the real economy and supply chain finance question. In reference to relations between finance and entities both at home and abroad, it is considered that small and medium-sized enterprises (SMEs) in Beijing-Tianjin-Hebei Region are hard to find financing and face a high cost in financing must be solved by the supply chain finance. Currently, supply chain finance has insufficient theoretical system with regard to the regional economy integration and also insufficient practice. It is considered that in-depth research shall be made on the mechanisms for the adaptability of the supply chain pattern to the regional real economy.
\end{abstract}

\section{Introduction}

In recent years, researches on real economy and finance industry both at home and abroad are on the rise. Economic globalization, industrial upgrade domestically, industry colony effect, and transformation of old industries have all promoted the co-development of real economy and finance industry [1].For Beijing, Tianjin and Hebei, Beijing, as the financial decision center, financial management center, financial information center and financial service center in China, put forward the positioning of "building a financial center with international influence" in 2008. Tianjin set its positioning as the modern financial service system and financial reform and innovation base through taking the chance that its coastal new area was selected to be the financial reform pilot area. As for Hebei Province, the economic hinterland of Beijing and Tianjin, it plans to build the financial cluster and financial service area surrounding Beijing and Tianjin through utilizing the excessive resources flown out of Beijing and Tianjin due to economic development difference [2].Difference in financial development conditions in Beijing, Tianjin and Hebei has made the cooperation and mutual benefit inevitable and thus become the internal driver for financial operation in the region. The cut-in point in financial cooperation in Beijing, Tianjin and Hebei will be based on how the financial services and financial resources can better satisfy demands from the regional industry transfer and upgrade and the matching real economy development.

\section{Current Research Situation and Development both at Home and Abroad}

In the industrial structure upgrade in China, banks are the main financial channel [3].Under the current financing pattern, the infrastructures, major industries and large enterprises have occupied the majority of bank loans, while the emerging industries and small and medium sized enterprises (SMEs) can only share the limited loans, which has hampered the industry upgrade. During 1999-2009, the primary and secondary industries had absolute strength and thus enjoyed steadily 
increased short-term loans from commercial banks. Yet the tertiary industry and SMEs were in the inferior position. Similarly, upgrade demands from different industries in Beijing, Tianjin and Hebei cannot be satisfied [4].Taking Beijing as example, according to the second economic survey by Beijing Statistics Bureau, by the end of 2008, there were about 252,000 SMEs, accounting for 99.7\% total enterprises in Beijing. In reference to main economic indicators like paid-up capital, total income, realized profit and taxes paid, SMEs accounted for more than $50 \%$ of all enterprises in Beijing, indicating that SMEs have become a major engine for economic development in Beijing. However, they faced the first problem of difficult and expensive financing. Yang Weifeng made correlation research on development of finance industry and real economy in Beijing, concluding that the low interest rate was adverse for real economy development. Also, the attraction of high-profit industries like finance and real estate has caused the crowding out effect against the real economy [5].

It is easy to understand that the current financing pattern becomes relatively ineffective for promoting economic transform and upgrade. In recent years, the financing means become diversified, with the rise in the direct financing, but it still takes a too low proportion in the total financing. Enterprises excessively depend on bank loans in their financing, resulting in the risk that banks have gathered a majority of social financing. This will be adverse to effective allocation of financial resources during the economic transformation period [6].

Under different economic development stages and development targets, the characteristics of real economic are different [8], thereby to have different demands on financial services proposed by the financing pattern. For instance, for the element driven growth relying on expanding investment and slow technical innovation, the real economies have put forward massive fund raising demand.

Whereas, for the technical innovation driven growth relying on technical innovation and industrial structure upgrade, real economies need not only the financing patterns to realize multi-capital financing, but also the control of possible risks during the innovation period.

As a matter of fact, the changes in the financing patterns rest with the functional demands from real economy activities, which will adapt to the ever-changing real economy to realize their development. At the same time, the financing pattern, as the reflection of the most important feature of financial structure, has decided the specific realization of financial functions.

Scholars [8] deem that during Beijing-Tianjin-Hebei Region integration, how to exert the driving effect of financial capital in boosting industrial upgrade will by no means repeat the road of the Pearl River Delta Region and the Yangtze River Delta Region and will be likely to make the functional adjustment in a larger region. The process shall follow the market law. In the process, problems include how can financing pattern adapt to the real economy will mostly rest with the exertion of financial functions. Then how to realize adaptability? What paths shall be followed?

Qian Long deems that [9] adaptability of financing pattern with the real economy means the matching between the financial functions provided by financing pattern and the financial service demands from the real economy under the economic development objectives.

Sun Wuqin proposed the optimal financial structure theory: real economics indifferent development stages have different demands for financial services. The optimal financial structure shall be able to satisfy the financial service demands of each stage, thereby to effectively promote economic growth [10]. 
Zeng Kanglin thought the cost and efficiency of financing method decided the financing method selected by an enterprise and pointed out the factors influencing cost and efficiency [11].

Lu Fucai studied the variation law of financing patterns of enterprises in countries of different stages, on which basis, established a theoretical frame for influence from enterprise financing on economy and finally applied this theory to guide the practical problems in China [12].

Liu Tie and Zhang Fei thought social capitals was able to work as the "soft guarantee" during the cluster enterprise financing. To take full advantage of enterprise colony strength, give play to the role of social capitals and build trust cooperation based network within the colony would become an efficient path to solve the difficulty faced by SMEs in financing [13].

Lin Yifu, et al. performed experimental tests on the panel data from 28 provinces and areas in China during 1985-2002, to analyze the relation between banking structure and economic growth, concluding that the rise in the market share of small and medium financial institutions will be helpful for economic growth in the current stage in China [16].

In company with increase in the supply chain scale in China, the financial gap will be the largest, in which case, many enterprise cannot get enough funds to support their normal operation [15].This condition is worsened by the global economic crisis. Collapse of a section might cause the Domino effect, thereby to spread to the entire supply chain [24].Lei Xiang, VP of Chunyu Supply Chain Management Co., Ltd. thought [7] the global supply chain required more complicated integration factors and was promoting new financing means. Then came the supply chain finance as the solution. In the meanwhile, supply chain integration also promoted development of the supply chain finance. Today the mainstream supply chain finance patterns include the inventory financing, receivable account financing and advance payment financing, featuring the movable property financing, extremely high operation efficiency, public attribute and strong liquidity. They worked like "blood" and "lubricant", to smooth the supply chain operation [24].

Supply chain financing seems to bring rich income for banks and also solve problems of SMEs. Yet the current domestic supply chain financial products mostly come from the consumer financial market. Yet the planning of enterprise financial products is targeted to large enterprises. This has not only caused over competition among banks, but also made SMEs unable to get sufficient financial services [25]. As for indirect financing, as shown in Table 1, the newly applied loans in Zhongguancun Science Park increased by more than RMB 120 billion, with each enterprise enjoying RMB 6.92 million. But the case is that SMEs only have receive a small part. As for the supply chain colony financing, there are only three financial products accounting for $2.94 \%$, as shown in Table 2. Data above indicate that the upstream product development and commercialized application is basically hard to move in Beijing, which has influenced the emerging of the new colonies and stretching and perfection of the industrial chain, and also restricted the development of real economy in Beijing. Therefore, the supply chain finance pattern innovation must be put on agenda. Especially under the background of Beijing-Tianjin-Hebei economic integration, how to give full play to the blood producing function of finance to promote real economy development in Beijing, Tianjin and Hebei becomes pressing.

Table 1 Financing Structures of 17353 High-tech Enterprises in Zhongguancun in 2009

Financing channel (100Amount (100Weight (\%) Average Remarks


million)

million)

(10,000/enterprise)

Total of newly increased

$1201.94 \quad 79.0766$

682.64

loans

VC amount

7.01

0.4612

4.04

Securities financing

69.8

4.5922

40.22

Stock equity financing

$230.97 \quad 15.1957$

Innovation fund

$10.25 \quad 0.6743$

5.91

Total

1519.97

100

875.91

Data source: 2010 Working Report of Zhongguancun National Independent Innovation Demonstration Area

Table 2 Credit Innovative Products of SMEs in Beijing (totally 102, provided by People's Bank of China Management and Operation Department)

\begin{tabular}{|c|c|c|c|c|c|c|c|c|}
\hline \multirow[b]{2}{*}{$\begin{array}{l}\text { Credit } \\
\text { products }\end{array}$} & \multicolumn{2}{|c|}{ Quantity } & \multirow[b]{2}{*}{ Feature } & \multirow[b]{2}{*}{$\begin{array}{c}\text { Scale } \\
(10,000)\end{array}$} & \multicolumn{4}{|c|}{ Credit product channel } \\
\hline & $\begin{array}{l}\text { Produc } \\
\mathrm{t} \\
\text { numbe } \\
\mathrm{r}\end{array}$ & roportio & & & $\begin{array}{l}\text { Large } \\
\text { commerci } \\
\text { al bank }\end{array}$ & $\begin{array}{l}\text { Local } \\
\text { commerci } \\
\text { al bank }\end{array}$ & $\begin{array}{l}\text { Foreig } \mid \\
\mathrm{n} \text { bank }\end{array}$ & $\begin{array}{l}\text { Polic } \\
\text { y } \\
\text { bank }\end{array}$ \\
\hline $\begin{array}{l}\text { Non } \\
\text { mortgage } \\
\text { and } \\
\text { unsecured }\end{array}$ & 7 & $6.86 \%$ & $\begin{array}{l}\text { Simple procedures, } \\
\text { rapid approval, } \\
\text { timely lending; loan } \\
\text { period within } 1 \text { year }\end{array}$ & $\begin{array}{lr}\text { Within } & 10 \\
\text { million } & \text { in } \\
\text { Bank } & \text { of } \\
\text { Communicati } \\
\text { on and } & 1 \\
\text { million rn } & \text { in } \\
\text { other banks } & \end{array}$ & 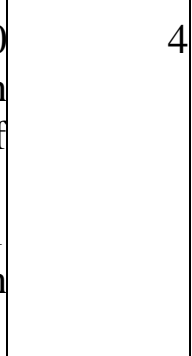 & 2 & 1 & \\
\hline \begin{tabular}{|l|} 
Mortgage \\
and \\
hypothecatio \\
n
\end{tabular} & 76 & $74.5 \%$ & $\begin{array}{l}\text { As long as } 10 \\
\text { years; } \\
\text { hypothecation loan } \\
\text { businesses mainly } \\
\text { expand financing } \\
\text { channels for SMEs }\end{array}$ & 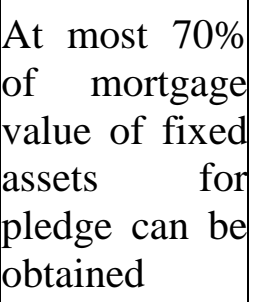 & 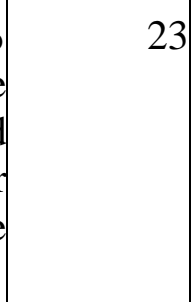 & & 5 & \\
\hline Supply & 3 & $2.94 \%$ & Flexible & Within & 2 & 2 & 1 & \\
\hline
\end{tabular}




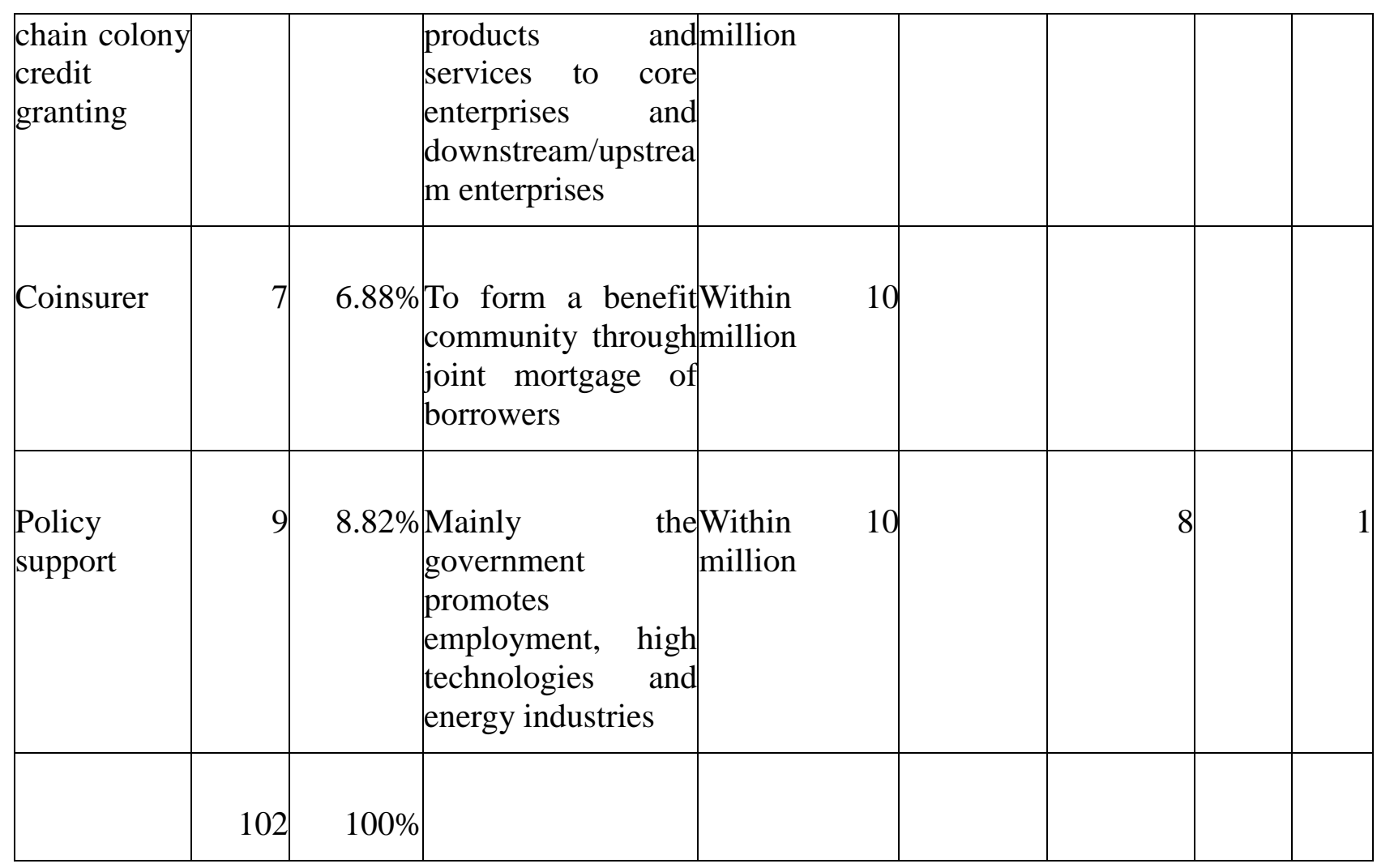

Data source: Zhongguancun Management Committee, Beijing SME Credit Products List

There are many new opinions and suggestions with regard to financial pattern innovation:

Along with the change in world economy, the globalization has caused production segmentation. Competiton between world entitites has become the competition between supply chains, resulting integration of industrial chains. The competition has involved in four aspects: first, information exchange; second, order forming; third, logistices, and fourth, finance [18].The integration management is based on the integration of industrial chain and has applied the features of each industry tocombine different industrial chains and enable public use of resources. It is also the megatrend of future supply chain integration [20], thereby to realize effective and efficient logistics, inforamtin flow, fund flow, value flow, to finally realize business flow, namely, to provide the largest value to clients at the low cost and high speed [21]. The main reason is that the integration of supply chains have built an integrowth network of supply chain finance [22].

Lei Xiang thought [7] the global supply chain integration was complicated becausae it crossed regions and time zones. Plus globalization, it would cross countries, which would encounter many communication and coordination problems. Such integration must be realized through the information technologies and internet technologies.Currently, domestic SMEs have low informatization level. Many financial institutions are providing supply chain and movable property based financing patterns. The curreent banks used the previous information survey pattern to realize risk control. Yet the current rating system of banks is still old-fashioned [19].Thus the supply chain financing is only the point-to-point financing. Even if some banks advocate they have new financing products, but they are only make the promotion. The real supply chain multiode financing to realize full supply chain online financing is seldom found, mainly due to difficulty in supply chain upstream and downstream integration. Especially the SMEs lack of informatization face very high cost in cooperation, which has infuenced expansion of the supply chain financing scale and the high enterprise cost, thereby to cause a high cost of the supply chain.Yang Hongyu, Jian Qiang [23] 
proposed the professional guarantee companies established by core enteprises with their industrial chain strength would conduce to solve the financial deal ends.

\section{Necessity to Study the Relation between Real Economy Development and Supply Chain Finance in Beijing-Tianjin-Hebei Region}

The existing literatures have no research on relevancy between supply chain finance and real economy, not to mention the research on supply chain finance pattern and regional real economy adaptability development, which makes this topic a new one in the circle. The existing researches have basically defined the supply chain finance research scope and operation pattern and mainstream product types, basically built the research framework of this field, despite of insufficiencies. The supply chain finance pattern is built on the product design of the practical operation, namely from point to point, but no supply chain consisting all sections has been found. The supply chain building, operation and substitution supply chain finance theoretical system has not been built, with the lack of regional economy integration based supply chain financing pattern and the financing solution expansion and perfection, and lack of supply chain finance pattern and regional real economy adaptability development.

(1) Theoretical meaning: under the backdrop of industrialization of Beijing-Tianjin-Hebei Region and based on the supply chain theory, the extended definition of the supply chain finance has been proposed. Also the theoretical analysis frame supported by the full-life cycle finance based on the supply chain composition, operation and substitution has been established. In reference to the existing literatures and theories and on the basis of field survey and study, in-depth exploration has been made into the adaptability mechanism and action mechanism of the supply chain finance pattern and the entity economic development in Beijing-Tianjin-Hebei Region.

(2) Practical value: adaptability established in regional real economy development and supply chain finance pattern has been taken as the research cut-in point to explore the incidence relation between the financing pattern and industrial reform and upgrade in Beijing-Tianjin-Hebei Region, propose policy advices on economic integration and supply chain finance pattern in Beijing-Tianjin-Hebei Region, in the hope of providing theoretical basis for financial cooperation innovation and policy making in Beijing-Tianjin-Hebei Region. This would help with building the information platforms by financial institutions and agents in Beijing-Tianjin-Hebei Region to realize online financing, expand business scale and strengthen competitiveness of real economy, provide theoretical support and guidance for making scientific and rational financing scheme and developing new financial products.

\section{Application Prospect}

Economic integration in Beijing-Tianjin-Hebei Region depends on industrial integration through industry transfer, industry upgrade and industry connection. Effective allocation of finance as the core resource will be essential. But in practical operation, the financial resources input patterns in the three regions are too many to place stress on the general financial efficiency, to result in the mismatching between the strong entity and strong virtual, to bring about week real economy. Secondly, the financial industry innovation of the three areas is so insufficient that it is unable to give full play to the fund allocation function of the real economy and thus influenced the real economy transform and upgrade efficiency. Only adopting the supply chain financing pattern can ensure the economic integration in Beijing-Tianjin-Hebei Region without disengaging real economy. Accordingly, under the background of industry integration and layout, transfer and upgrade of 
industries in Beijing-Tianjin-Hebei Region, the regional supply chain will be built and the financial resources injected to the proper section on the industrial chain. Considering the needs of real economy, the innovation of supply chain finance pattern will be made, to effectively enhance the operation efficiency of the supply chain and lower the operation cost, thereby to promote the regional industrial structure upgrade and promote economic integration and sustainable development of Beijing-Tianjin-Hebei Region. This project will primarily produce the research report and theses and provide theoretical guide for economic integration development in Beijing-Tianjin-Hebei Region. It will be of reference value.

\section{Reference}

[1]Meng Xianglin. The financial integration of Beijing Tianjin Hebei: With the establishment of Beijing Tianjin Hebei bank as the starting point for the analysis of ideas. Journal of Qingdao University of Science \&amp; Technology (SOCIAL SCIENCE EDITION) 2010,(1):1-6.

[2] Chinese United Daily, 2014.3.24 page B02.

[3] Zhang Zongxin. Chinese financing system innovation research. Beijing: Chinese finance press, 2003

[4] Du Qiang. Binhai New Area Financial Reform and innovation to promote regional financial cooperation for Bohai ring, 2010, (10): 34-35.

[5] Yang Weifeng. Analysis of the factors that restrict the development of economy in Beijing City Economic Research Introduction in 2013 twenty-third

[6] Zhu Qifeng. The development of private equity funds on China. XiaMen: Xiamen University, 2009

[7] ifeng.com Finance: http://finance.ifeng.com/bank/zzyh/20120116/5459835.shtml

[8] Qian Chen. Grasp the development trend of the real economy, The economy of Zhejiang, December 10, 2012

[9] Qian Long. China financial sector and the real economy interactive development of empirical test $[\mathrm{J}]$ Statistics and decision 2013 fourth

[10] Sun Wuqin. The theory of financial structure and entity economy efficiency. The management of the world 2004 (5): 134 - 135

[11] Ceng Kanglin. How to treat the direct and indirect financing. Journal of financial research, 1993 (10): 7 - 11

[12]Lu Fucai . The efficiency of enterprise financing analysis. Beijing: Graduate School of China Academy of Social Sciences, 2000

[13] Liu Yi, Zhang Fei. Based on the analysis of the social capital of the SMEs cluster financing. Journal of Hunan University (SOCIAL SCIENCE EDITION), 2009 (5): 67-72.

[14] Bhide, A. The Hidden Costs of Stock Market Liquidity, Journal of Financial. Economics, 1993,34 (2): 31 - 51

[15] Zhou Liyan. Study on the relationship between the cointegration analysis of financial and real social financing scale based on the economic perspective, Money Economy, October 2012

[16]Yifu Lin ,Sun Xifang. The banking industry structure and economic growth, Economic research, 2008 (9): $31-45$

[17] Liu Huifeng. On the role of accounting conduction in the interaction of real economy and fictitious economy, Accounting Research . June 2012

[18] Bai Yanqi. Supply chain finance and industry cluster characteristics and relations, Foreign Trade in 2012 ninth

[19] http://info.1688.com/detail/1120697346.html

[20]. Yang Xin and other experts. An empirical study on the impact on enterprise relationship benefits demands enterprise strategic mode selection cases in Beijing high tech industry cluster [J]Journal of Tsinghua University in 2011 fifty-first.

[21] Wu Chunjie. On the financial support for the development of industrial clusters of small and 
medium-sized enterprises survey, Times financial 2012 twelfth

[22] Wang Ting, Zhuang Xiaoyun. The supply chain financial structure model, Logistics Technology in 2010 eighth industrial symbiosis network based on

[23] Yang Hongyu, Jian Qiang. Relying on the industry chain the farmers difficult to guarantee, Chinese urban and rural financial report, 2013-01-23

[24] Xia Taifeng. Research on Supply Chain Finance in August 2011, financing of small and medium-sized enterprises based on the perspective of Zhejiang University

[25]Bai Yanqi. Supply chain finance and industry cluster characteristics and relations, foreign trade in 2012 ninth 